\title{
In memoriam: Professor Janina Rafałowska
}

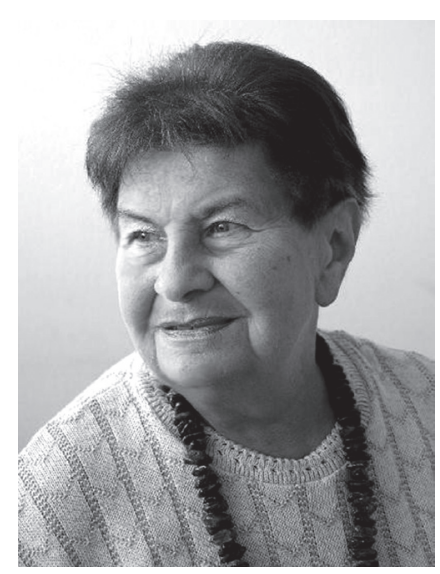

With great sadness, we share the news that Professor Janina Rafałowska passed away on June $30^{\text {th }} 2017$ at the age of 88 . She was a pioneer of neuropathology in Poland, with impressive clinical and scientific achievements. She was an excellent clinician in neurology, an outstanding neuropathologist, a prominent scientist, a teacher of several generations of medical students, and a true friend to many of us. Her death is a loss to the entire community of neurologists and neuropathologists. For many years she was an active member of the Editorial Board of Folia Neuropathologica, in which she reviewed the submitted articles on clinical and experimental neuropathology.

We will miss her professional passion and her wisdom, but first of all her warmth, goodness of her heart, and humanity.

Editorial Board

\section{Memory}

Professor Janina Rafałowska was born on April $21^{\text {st }} 1929$ in Warsaw. She graduated from the Medical Academy in Warsaw in 1954 and entered the Department of Neurology in the Medical Academy of Warsaw as a volunteer, then as a scholarship holder for the Ministry of Health. Next, she became an assistant, assistant professor, associate professor, and finally professor in the Department of Neurology. In 1956, after passing the specialisation exams, she received the title of neurologist, in 1960 specialist neurologist, and in 1977 specialist neuropathologist. In her early career, Professor Rafałowska worked mainly as a clinician in the Neurological Department, and then in the Stroke Department of the Neurological Clinic. At that time, she was primarily interested in clinical problems, which was reflected in the 21 scientific articles she published in 19551970. In 1962 Professor Rafałowska started to work in the Laboratory of Morphology of the Central Nervous System, founded by the excellent neuropathologists Professors Orzechowski and Opalski in 1928. The laboratory was then located in the basements of the Clinic, in the so-called "catacombs", where the shelves were lined with jars containing valuable formalin material - brains - in the narrow corridors. The quite dark atmosphere of this place was filled with cigarette smoke, the smell of coffee mixed with the smell of formalin, and the sound of scientific discussions conducted by the Professor. In 1970 Professor Rafałowska became the head of the Laboratory, which was renamed the Laboratory of Neuropathology. As a neuropathologist, she was interested predominantly in vascular diseases of the brain and spinal cord, aging processes of the nervous system, and neurodegenerations, especially amyotrophic lateral sclerosis (ALS). In 1968 she received her PhD in medicine based on the thesis "Morphological changes of the walls of vessels in the amyotrophic lateral sclerosis" and submitted a habilitation dissertation in 1976 entitled "Selected problems of development and aging of nervous system". In 1989 she was awarded the title of Professor of Medicine, and from 1988 to 1990 she was the head of the Neurological Clinic in Warsaw Medical Academy. During her long career she gained scientific experience in the Neurological Institute of the Russian Scientific Academy in Moscow and in New York State Institute for Basic Research in Developmental Disabilities in the USA. 
From 1987 she started to work as a neuropathologist in the Medical Research Centre of the Polish Academy of Sciences. In 2000 she was appointed as Head of the Department of Neuropathology and held this position until 2005. She continued her scientific research in the Department of Experimental and Clinical Neuropathology until the last days of her life.

Her most recent work focused on sporadic cases of amyotrophic lateral sclerosis and transgenic rat model of familial form of ALS, and vascular changes during various pathological processes, especially Cadasil and brain aging.

Professor Rafałowska was also an excellent teacher of students, young medicine adept, neurologists, and neuropathologists. Her lectures were illustrated with her hand-made drawings, and the final mark of the exams was written in green ink. She not only wrote with green ink, but also collected figures of owls, and she was known for her characteristic sayings. One of them was "in nature nothing is lost", used most often when on a desk covered with piles of papers among which she could not find some important notes. And indeed, "in nature nothing is lost", because the Professor will remain forever in the memory and hearts of the people who knew her and liked her.

Dorota Dziewulska Ewa Matyja

Milena Laure-Kamionowska 